\title{
'We Realised We Needed a New Approach': Government and Law enforcement Perspectives on the Implementation and Future of the Drug Decriminalisation Policy in Vietnam
}

Hai Thanh Luong ( $\nabla$ haithanh.luong@rmit.edu.au )

RMIT University https://orcid.org/0000-0003-2421-9149

Luc Trong Hoang

The People's Police Academy of Vietnam

Toan Quang Le

People's Police Academy of Vietnam

Tuan Anh Hoang

The People's Police Academy of Vietnam

Mai Thanh Vu

The People's Police Academy of Vietnam

Huyen Quang Tran

The People's Police College of Vietnam

Nicholas Thomson

The University of Melbourne School of Population and Global Health

\section{Research}

Keywords: Decriminalize drug use, drug policy, harm reduction, police officer, Vietnam

Posted Date: March 25th, 2020

DOI: https://doi.org/10.21203/rs.3.rs-18285/v1

License: (9) (i) This work is licensed under a Creative Commons Attribution 4.0 International License. Read Full License

Version of Record: A version of this preprint was published at International Journal of Drug Policy on January 1st, 2021. See the published version at https://doi.org/10.1016/j.drugpo.2020.102990. 


\section{Abstract}

Background In 2009, Vietnam officially decriminalized drug use through amendments to the criminal law. The amendments specifically outlined that drug use would be seen as an administrative sanction, but not a criminal offence. This legal transition has not been without its implementation challenges and police particularly are have struggled to balance their role between drug law enforcement and decriminalisation. Despite being a health-orientated drug policy amendment, in practice it has meant that police can send suspected drug users to compulsory treatment centres without judicial oversight and people who use drugs continue to face challenges in their interface with law enforcement which can negatively impact access to harm reduction and community-based treatment programs. This paper explores the perspectives of policy makers and law enforcement officials in Vietnam and provides some insights and considerations into how the amended law was implemented and how it could be made more effective in improving both health and safety for all people in Vietnam.

Methods To understand government and policing perspective on amended changes to the Criminal Code in 2009 and its subsequent implementation, this mixed methods research combined content analysis of a number of core legislations in terms of drug control policies in Vietnam with perspectives and insights from 14 key informant interviews from people representing a range of relevant Vietnamese Government $(n=10)$ and non-government agencies $(n=4)$.

Results While most interviewees recognised that decriminalizing drug use in Vietnam was designed as a a progressive and health-oriented drug policy, many participants acknowledged the ongoing disconnect between the health intent of the policy and the police-led oversight of its implementation in the community. Part of this disconnect was explained by the lack of training and clear protocol that would enhance the police in their ability to contribute to the health intent of the policy rather than continue to view drug use through a drug law enforcement only lens. A current pilot initiative by Hanoi's People Committee to implement a model of assisted referral for people who use drugs to community-based health, social and legal support may provide an example of how to situate decriminalisation policy within a broader context of harm reduction interventions through the design and trial of clear protocols for how law enforcement agencies can actively engage and support the process of diversion into harm reduction and community-based treatment.

Conclusions Since the inception of the amended law there has been very little review and analyses of its implementation progress and its challenges. This is the first study to review and assess the progress of decriminalizing drug use since the policy intervention in 2009 with a specific focus on the perceptions of the policy for Vietnam's drug control in policing. It discusses insights and considerations from government, law enforcement officials and civil society organisations to develop a deeper understanding of how harm reduction interventions - including decriminalisation - can co-exist within a broader and entrenched drug control strategy in Vietnam.

\section{Introduction}


The implementation of the Renovation Period (Doi Moi in Vietnamese) designed to drive economic reform and improve social and economic prospects for the country in 1980s was also accompanied by significant increase the use of heroin in Vietnam. In response the Government of Vietnam criminalized drug use through a specific regulation (article $185 \mathrm{I}$ ), punishable by imprisonment between three months (minimum with the first case) and five years (maximum with re-offending) in 1997 (the fourth amendment of the 1985 criminal code). Between 2000 and 2007, the number of drug users who had recorded a criminal conviction due to their drug use rose to 178,305 people and by the end of 2008 drug users with complex needs were reported in almost every province, district and commune of Vietnam [1]. The implications of increasing drug use in Vietnam was highlighted by its interface with systems of incarceration where the proportion of legal violations among young drug users was reported as 100 times higher than that of young people who do not use drugs. Furthermore, the number of drug offenders made up over $40 \%$ of the populations of prisons, detention camps, and temporary custody houses and the prevalence of prisoners who had a history of drug dependence was over $28 \%$ [2].

The high prevalence of HIV among people who injected drugs led to the formalisation of the harm reduction law introduced in 2008 to prevent and control HIV/AIDS through propaganda, mobilization and encouragement of the use of condoms, clean syringes and needles, treatment of opiate dependence through access to methadone and other harm reduction intervention measures [3]. One year later, the Government also issued guidelines for methadone treatment for opiate dependence and also commenced the first methadone pilots in Ho Chi Minh City, Hanoi, and Haiphong before the Law on Drug Control and Prevention (LDCP, 2008) formalised it as one component of harm reduction in the in the treatment of people who used drugs (article 34a). Based on the high rates of relapse among people who used drugs from the compulsory treatment centres and growing recognition that criminalising drug users had not decreased drug use or drug offending, the National Committee on Social Affairs [4] emphasized the need to understand drug use and addiction as a type of chronic diseases which led to the official recommendation to the National Assembly to decriminalize drug in Vietnam.

On 11th April 2008, at the official meeting of "Draft Report on Implementing Resolution No.16/2003/QH11 to organize, manage and provide jobs for drug users after rehabilitation", all members of National Committee of Social Affairs of the National Assembly strongly supported the proposal to decriminalize drug use (article 199, Criminal Code of Vietnam 1999 - CCV). One year later on the 19th June 2009, the 5th Session of the XII National Assembly Period passed the CCV supplement and amended article decriminalizing drug use which took effect on the 1st January 2010. Accordingly, the amended law states that the use, purchase, and possession for use of any illicit drugs in public or in private, is no longer to be considered a criminal offense, but rather an administrative sanctioned offense [5]. Under the new legal framework all drugs were decriminalized but not legalized and drug trafficking continued to be prosecuted as a criminal offense that could lead to the death penalty [3]. Accordingly, drug possession for personal use and drug usage itself are still legally prohibited through the application of an exclusive administrative sanction that can result in people being sent to compulsory treatment centres (CTCs). This study focuses on three main questions: Why Vietnam decided to decriminalize drug use in 2009? How did an overreaching drug control strategy change in response to decriminalisation? 
And how Vietnam combines harm reduction within a 'drug treatment', 'drug control' and 'decriminalised' context?

\section{Methods}

To answer these questions, we combined a policy desk review with key informant depth interviews (KI). The desk review included legislative documents of the communist party, government and national assembly that were collated and analysed using Legal Norm's Library of Vietnam software via the thuvienphapluat.vn platform with a professional account to request both Vietnamese and English version documents. KIs were held with ten representatives from Vietnamese Government officials from the National Committee of Social Affairs, National Committee of Legal Issues, Ministry of Labour, War Invalid and Social Affair (MOLISA), Ministry of Public Security (MPS) and the Ministry of Health (MOH). Kls were identified from a range of key government policy areas as well as five police officers from ward and district level within Hanoi and Nghean province. In addition, depth interviews were conducted with representatives from the United Nations (UNODC and UNAIDS) and civil society organisations (Supporting Community Development Initiatives - SCDI, and Institute of Social Development Studies ISDS) all of whom have observed and engaged with the decriminalisation policy since its inception in 2009. A draft $\mathrm{Kl}$ interview guide was developed with inputs from harm reduction researchers from the University of Melbourne and police researchers from the Peoples' Police Academy of Vietnam as well as program officers from SCDI in Hanoi. Between April and July 2019, 14 individuals representing key agencies were interviewed. Semi-structured guides investigated factors and causes of Vietnam's decision to decriminalize drug in 2009 and sought to identify potential barriers during and post the 2009 decriminalisation amendment. Given that the conflicting HIV/AIDS Law and LDCP may have elicited criticism of government policies - as well as out of respect for personal privacy rights of law enforcement and government's officials - interviews were not tape recorded, except for the interview with the representative of UNODC. KIs did not provide permission to share the entire transcripts so handwritten notes capturing the main points of the interviews in Vietnamese language formed the interview summaries and were seen and approved by each participant before analysis. Transcripts of interview summaries were prepared and analysed using thematic analysis after all transcripts were translated by a professional fluent in both Vietnamese and English and read for accuracy by the researchers. These descriptive transcripts were analysed by NVivo 12 for Mac and quotes have been annotated where practically possible to provide participant insights and after permission was granted by the interviewees.

\section{Findings}

\section{Understanding of the Rationale for Decriminalisation Policy}

Since 1999, alongside sex workers, drug users were identified as 'social evils' and linked directly to the HIV epidemic in Vietnam and often sent to mandatory rehabilitation of up to two years in a CTC. As the numbers of people detained in CTCs rose exponentially, several participants commented that the workloads of police and staff at the CTCs became unmanageable [6]. Significant international criticism 
of the negative impacts to human rights in the CTCs created an internal country debate $[7,8]$, as a representative of MOLISA commentated,

You need to remember that after the second CCV passed in 1999 with a focus on the criminalizing of drug use in article 199, it led to repressive enforcement approaches for those with drug addictions. Vietnam then endured a significant overcrowding of the prisons with people who used drugs across the whole country. That was matched with more enforcement to populate the CTCs with drug users and then manage the workload and the growing activist dissatisfaction with the CTCs. The health care of drug users suffered, and the rate of drug users did not decline nor did the rate of HIV/AIDS among people who injected drugs. It was obvious that criminalizing drug use was not the excellent solution that it was meant to be (Interviewee \#10).

Vietnam's 1999 CCV aimed to strictly regulate drug users as offenders, rather than people with health problems highlighted by several participants who noted;

We thought that the harder punishment would lead to easier control of drug user numbers and decrease drug trafficking however this was a miscalculation on our behalf (Interviewee \#6).

At that time, we considered that reducing demand via putting drug users in jail would be effective measures in reducing supply...however, that was wrong (Interviewee \#5).

From 1999 to 2009, between incarcerating people who used drugs as a criminal offense or alternatively sending people to CTCs under an administrative violation, Vietnam did not demonstrate any decrease in drug demand [3] with an increase in the number of drug users registered with authorities from 55,455 in 1994 to 178,305 by the end of 2007 and the number of CTCs increased from 56 in 2000 to 123 by end of $2010[6,9]$. Between 2000 and 2010, approximately 309,000 people had been detained and treated at the CTCs $[6,9]$. Yet there was a growing realization from a range of anti-narcotics' authorities from central level down to the ward police that the relapse back to drug use from people leaving the CTCs was estimated at $80-90 \%$ and in some provinces reached $95-100 \%$, [10]. Furthermore, HIV prevalence amongst people who injected drugs continued to increase which had serious implications for the health system of Vietnam. A key informant who was also a medical doctor before joining MOLISA, recalled;

Putting them [users] in the jail or CTCs without necessary interventions and effective solutions in terms of health and treatment just increased the risk of infectious disease to this population of people (Interviewee \# 10). 
The lack of success of the drug user criminalization approach became obvious to both the Party-State and the broader community $[7,8]$. This situation forced officials to begin to re-consider how to re-structure drug policy in Vietnam. At the same time the international literature investigating the effect of decriminalization policy on rates of drug use from predominantly western settings either indicated no remarkable rise in drug use after decriminalizing $[11,12]$, a marginal increase $[13,14]$ or difficulties reporting any trend on drug use $[15,16]$. The evaluation of the Portugal model however highlighted that decriminalisation of drug use had resulted in decreased crime, decreased incidence of HIV and increases in the number of people voluntarily seeking drug treatment [17]. This model was reviewed by Vietnamese policymakers and enabled learnings and momentum towards a decriminalisation policy in Vietnam [3].

\section{Overcoming Political Attitudes, Ideologies and Expanding Harm Reduction}

Despite many Party officials being in favour of closing the CTCs and voting for decriminalisation due to an entrenched culture of police-led arrest of drug users and the economic interests in the local government management of CTCs, there was resistance to the decriminalisation policy amendment [8]. Therefore, when the National Committee of Social Affairs called for decriminalization drug use and the NA voted in June 2009 there was not unanimous support for the policy;

At least 35,7\% (176 participants) disagreed and 2,23\% (11 participants) did not vote among the 449 attending participants. This left only 53,14\% (262 participants) agreeing to decriminalize drug use reflecting conservative hesitations although it did pass (Interviewee \#1).

When Vietnam decriminalized drug use in their criminal law system, many worried about the effectiveness of this change because harm reduction itself had not yet become ingrained in Vietnam and the CTCs system was not being dismantled $[8,18,19]$. Although Vietnam was concerned about the HIV prevalence among PWUDs the adoption of harm reduction was very slow, and it wasn't until the National Strategy for HIV Prevention and Control and its Law passed in 2004 and 2006 respectively that harm reduction was fully endorsed which health officials knew was too slow in happening.

As doctors and nurses, we worried and concerned that this process had been too slow (Interviewees $\# 1,10,13)$.

In early 2009, a methadone maintenance treatment (MMT) program was piloted at six community-based treatment facilities in Hai Phong and Ho Chi Minh City providing MMT to 1,685 patients [20]. Of these patients, 979 were enrolled in a two-year evaluation study between January 2009 to September 2011 in a project supported by USAID, PEPFAR [21] which showed that 'MMT significantly reduced illicit heroin use in participants and, among those who did continue using heroin, greatly decreased frequency of injection.' 
MMT was rapidly scaled up and by 30 June 2012, the national MMT program had treated nearly 10,000 patients in 12 cities and provinces [22]. The MMT program outcomes have improved health outcomes and proved more cost effective than CTCs and have been shown to decrease crime [7] as well as build further nationally relevant evidence of the benefits of patient-centered treatment as part of a harm reduction framework [23].

\section{Police Engagement at the Interface of Drug Control and Harm Reduction}

Within a fairly short period of time, decriminalisation, community based MMT and an active needle and syringe distribution program (NSDP) were all coexisting within an environment that still prioritised strict drug control where drug users continued to be regularly under threat of arrest by police. The NSDP, managed by the Ministry of Public Health, contributed to reducing the rate of needle and syringe sharing among injecting drug users and a reduction in HIV prevalence among injecting drug users from $29.35 \%$ in 2002 - 2003 to $19,66 \%$ in 2009 [20]. Yet almost all police officers at that time thought the NSDP was leading the users to relapse $[1,24]$ and police continued to be taught in their police training that using illicit drugs, even once would inevitably leads to prolonged addiction [25].

These divergent perspectives between the health sector and law enforcement contributed to the ongoing police support for abstinence-based approaches such as CTCs. Specific work examining the role of police in harm reduction programs in Vietnam $[24,26,27]$ highlighted that police would prioritize arresting and detaining drug users rather that support their access to harm reduction which is a situation that still prevails today. It took almost five years after the implementation of the decriminalisation policy for the first national consultation workshop to discuss the development of police training materials on harm reduction interventions and the prevention of HIV, which largely focused on the occupational health and safety of police.

That's why during this gap time [2009-2013], we did not know exactly what role and responsibilities were in dealing with drug users to support their access to the standard harm reduction interventions. All we were really taught was how to protect ourselves to avoid HIV exposer from users and in case of exposure, how to promptly handle to minimize HIV risk (Interviewee \#2).

Police officers in this study further affirmed that;

'...drug use and addiction are the fastest pathways to criminal behaviors.... and that drug use makes up the highest number of offenders across society' (Interviewee \#7) 
'...preventing and combating all drug-related crimes are our most prioritized duties. Nothing more, nothing less' (Interviewee \#4).

There has been virtually no training given to police about harm reduction or the implementation of the decriminalization policy [24, 26].

Despite the decriminalisation policy, the perceived ineffectiveness of community-based treatment and a persistent political commitment to anti-drug rhetoric such as "Drug free ASEAN" continues to see the Government of Vietnam implement strict management and tough control over drug users via CTCs which expanded in number to 123 centres between 2012-2015 after an initial scaling down [25,28]. Human resources and technical capacities still limit the effectiveness of community-based treatment and relapse remains common which undermines the police and community support for health-based drug policies and perpetuates drug-related stigma [19]. The police team in Nghean commented on the issue of under resourced community-based treatment programs;

If resources are not enhanced, it will be impossible and they [local authorities] must take over and deal with the task, including our policing duties [collecting and sending users to courts], and therefore, up to now, most of the post-detainees who have returned to their places of residence have not been supported to stabilize their lives, which is one of the reasons for their early relapse (Interviewee \#2)

Indeed, among local authorities, ward police officers are considered the frontline force to manage postdetoxification users when they re-integrate into community as well as support and guide them to stabilize their life $[18,25,26]$. Yet police do not always see the role as holistically as it is described above;

Our duties are still to monitor and call them anytime if we suspect they have relapsed and are involved in other criminal activities. Supporting them to stabilise their life is not our duty because we have to carry out a number of different inquires (Interviewee \#5)

From the establishment of the professional anti-narcotics police force in 1997 through to the decriminalisation of drug use in 2009, there have been irregular meetings and symposiums between $\mathrm{MOH}, \mathrm{MOLISA}$ and MPS focused on supporting the police to avoid occupational HIV risk in their work combating drug-related crimes $[28,29]$. Occupational HIV risk reduction is an important part of police safety but it is unlikely to improve their engagement, attitude or willingness to support health-orientated drug policy. When asked what a national harm reduction training for police should include, a retired senior police officer suggested,

The ideal training framework is on how police can support service provision for PWUDs. It should be designed in order for police to implement at scale across an entire policing service and thereby significantly enhance the ability of police forces to contribute to the national drug policy's response. The 
program should be implemented across policing education at all levels; from basic recruit training through to ward police and indeed with senior leadership positions in anti-narcotics police forces (Interviewee \#6)

\section{Efforts to better integrate policing and decriminalisation}

In February 2019, the Hanoi People's Committee issued Plan No.40/KH-UBND titled "Social and Legal Consulting, Assisted Referral Model for People who Use Drugs"[1]. A pilot initiative to support long-term drug dependence treatment through referrals to health, legal and social support services to help people on treatment integrate into the community, prevent relapse and achieve the highest physical and mental health. It was also designed to ensure police had a definitive option to contribute to health-orientated approaches to drug use. Based on a model of police assisted diversion (PAD) where police assist PWUDs connect with the health, social and legal services rather than arresting people or sending them to CTC. It is a partnership project involving police, government and civil society organisations. One of the project partners from civil society noted,

This is the first model in Vietnam to trial the participation of police in introducing, connecting and supporting drug user access to voluntary counselling and support agencies in their community. An initiative implemented in two districts with six communes in Hanoi and it will hopefully help contribute to concretize harm reduction in policing (Interviewee \#1).

Observers of the pilot including a senior officer of MOLISA and a retired police officer commented;

We call it [this model] voluntary treatment in the community supported by relevant medical, social and legal services (Interviewee \#10)

This pilot will demonstrate the abilities, duties, and responses of police officers to cooperate and collaborate with multiple civil society and social affairs in harm reduction approach, if their high-ranking level in the MPS support it then it will be extended other locations in the future (Interviewee \#6)

Based on Seattle's Law Enforcement Assisted Diversion (LEAD) program [30], the goal of the model is to create conditions for early stage drug users to participate in drug treatment as well as prevention and treatment of HIV, Tuberculosis and Hepatitis B/C in their respective localities. The project aims to reduce the number of people referred to compulsory detoxification, reduce engagement in crime and improve the quality of life of people who use drugs. Planning No.40 stipulates that local ward police must provide drug users with assistance to access support, counselling, drug dependence treatment and referral to health, social and legal services [30]. This model will hopefully illustrate that decriminalisation and a 
health orientated approach to drug use is more effective than sending PWUDs into CTCs for up to two years. One participant noted,

Clearly, when the courts sentenced people to death it pushed the penalty frame for drug crimes to the highest punishment, but drug-related crimes did not decrease at all. So, when making policies, we must not think that increasing penalties is an effective solution. How is the punishment commensurate with the behaviour? Drug use and drug trafficking are totally different activities (Interviewer \#6)

[1] Hanoi is the first city in the country to pilot the model, which is co-managed by the MOLISA and the Hanoi Department of Social Evils Prevention, with the technical support from the Centre for Supporting Community Development Initiatives and financial support by SAMHSA. In the first stage, the model has been implemented in two districts - Long Bien and Nam Tu Liem with 6 communes (Ngoc Lam, Ngoc Thuy, Bo De, Cau Dien, My Dinh 1 and Xuan Phuong). It officially operates throughout 2019-2020 and is expected to work with 150 people. The financial supports for the year of 2019 is around VND1 million (USD 450,000).

\section{Discussions And Conclusions}

Our research sheds light on the perspectives of key officials from across central, provincial, and commune levels of government on the process and implementation of the decriminalisation policy over the last ten year. Police attitudes and approaches to the decriminalisation of drug use have slowly improved since initial implementation in 2009. Yet a number of challenges remain to ensure that the 220,000 people who use drugs in Vietnam are truly given health-orientated opportunities to achieve health and social wellbeing during times they are using drugs and times that they are not.

The legal and policy environment to support health-orientated approaches to drug use is now well articulated yet the operational integration of these policies against a persistent drug control strategy undermines the ethos and intent of the progressive policy environment. Given the significant power that police have in overseeing the co-existence of decriminalisation, harm reduction and drug control there is a stark imbalance in how the police perceive and prioritise health versus punishment. It is clear that decriminalisation has been used to administratively deliver people who use drugs into CTCs - and then once they are released and redirected to community-based treatment - it is the police who judge the success of failure of the individuals in their required persistence of abstinence.

Many officials interviewed for this study acknowledge the need to re-instruct and retrain law enforcement officials so they can enhance access to health services for people who use drugs rather than act as a vehicle to forced detoxification. However, this will not be successful unless a dismantling the CTC's 
system is enacted and thus removes the option to send people to compulsory detoxification. Vietnam has done a remarkable job of building its own evidence base highlighting the effectiveness of communitybased MMT, so it now needs to divest itself from CTCs and invest in the cascade of harm reduction options including NSDP and community-based MMT.

The police need a clear protocol that lays out a code of conduct and specific instruction that police employ to ensure health service access for people who use drugs and this protocol needs to be embedded in police training from the Peoples Police Academy through to police already working across the country. Supporting these efforts by changing the traditional metrics of police success from arrest to diversion will reward and incentivise police behaviour. A national pre and post survey conducted before and after the delivery of police training around the protocol will build a national platform to monitor and evaluate ongoing shifts in police attitudes and practices in the decriminalisation environment. The evaluation and lessons learned from the current Planning No.40 in Hanoi 'police assisted diversion' (PAD) program will be important in designing future police protocol and instruction.

The achievement in decriminalizing drug use in Vietnam should be applauded and as the Government of Vietnam now considers new drug laws our recommendation is to continue to develop and support the police to play a much more health orientated role to drug use. Doing so will continue to improve service provision to affected populations and support broader community safety and well-being.

\section{Abbreviations}

CCV: Criminal Code of Vietnam; CTC: Compulsory Treatment Centre; ISDS: Institute of Social Development Studies; LDCP: Law on Drug Control and Prevention; MMT: Methadone Maintenance Treatment; MOH: Ministry of Health; MOLISA: Ministry of Lab or, War Invalid and Social Affair; MPS: Ministry of Public Security; NSDP: Needle and Syringe Distributions Program; PAD: Police Assisted Diversion; PWUD: People Who Use Drug; SCDI: Centre for Supporting Community Development Initiatives; and UNODC: United Nations on Drugs and Crime

\section{Declarations}

\section{Acknowledgements}

The authors would like to thank Dr Oanh Thi Hai Khuat, Executive Director of Centre for Supporting Community Development Initiatives (SCDI); Greg Denham, Law Enforcement Action Partnership Australia (LEAP); Jay Jordens, Education Program Manager (Judicial College of Victoria); and Gloria Lai, Regional 
Director of the International Drug Policy Consortium for their helpful recommendations during conducting data collection and attending conferences

\section{Authors' contributions}

HTL designed the study with contributions from NT. TAH, LTH, HQT, and MTV are main authors to collect and analysis data in Vietnam's context. HTL, TQL, and NT provided insight into the interpretation of the results and assisted with writing the manuscript. HTL wrote the first draft of the manuscript and also conducted the data analysis then worked together with TQL and NT to review and revise a series of draft revisions through to the final version. All authors have read and approved the final manuscript.

\section{Funding}

One part of fundings from the International Drug Policy Consortium (IDPC) supported the first author $(\mathrm{HTL})$ to conduct his fieldwork in Vietnam

\section{Availability of data and materials}

The datasets generated and/or analysed (Vietnamese language) during the current study are not publicly available due participant's request to respect for private information but are available from the corresponding author on reasonable request.

\section{Ethics approval and consent to participate}

The study was approved by the Institutional Review Board of the People's Police Academy of Vietnam (Hanoi). All participants provided informed consent to participate in the study.

\section{Consent for publication}

The participants consented to the use of their data for research publications.

\section{Competing interests}

The authors declare that they have no competing interests.

\section{Author details}

1. Researcher, Institute of Research and Developemnt, Duy Tan University, Danang 550000, Vietnam; Honorary Principal Research Fellow, School of Global, Urban and Social Studies, RMIT University, Melbourne VIC 3000, Australia (haithanh.luong@rmit.edu.au).

2. Deputy Dean, Faculty of Forensic Science, the People's Police Academy of Vietnam, Co Nhue 2 Ward, Bac Tu Liem District, Hanoi 100000, Vietnam (hoangluchvcsnd@gmail.com) 
3. Lecturer, Faculty of Criminal Investigation, the People's Police Academy of Vietnam, Co Nhue $\mathbf{2}$ Ward, Bac Tu Liem District, Hanoi 100000, Vietnam (lequangtoant32@gmail.com)

4. Direct, Department of Human Resource, the People's Police Academy of Vietnam, Co Nhue 2 Ward, Bac Tu Liem District, Hanoi 100000, Vietnam (hoangtuan2668@gmail.com)

5. Senior Lecture, Faculty o Fundamental Policing, the People's Police Academy of Vietnam, Co Nhue 2 Ward, Bac Tu Liem District, Hanoi 100000, Vietnam (thanhmaitph@gmail.com)

6. Vice-Rector, the People's Police College of Vietnam, Khuat Duy Tien Street, Thanh Xuan Bac Distric, Hanoi, 100000, Vietnam (bangkien06@gmail.com)

7. Department of Public Health, Environment and Society, London School of Hygiene and Tropical Medicine, 17-17 Tavistock Place, Saint Pancras, London, WC1H 9SH, United Kingdom; Nossal Institute, Melbourne School of Population and Global Health, University of Melbourne, 207 Bouverie Street, Carlton VIC 3053, Australia (nicholast@unimelb.edu.au)

\section{References}

1. Hanh, T.M.P., Quan Ly Nha Nuoc ve Cong tac Phong, Chong Ma Tuy o Viet Nam trong Thoi ky Hoi Nhap, in Quan ly hanh chinh cong. 2016, Hoc vien hanh chinh quoc gia: Hanoi, Vietnam [trans: Hanh, T.M.P. (2016). State Management on Prevention and Combat Drugs in Vietnam in the Integrated Period. (PhD), Academy of National Administration, Hanoi, Vietnam].

2. National Assembly Standing Committee, Report on Explanations, Hearings, Adjusting in Draft Law on Drug Control and Prevention [Vietnamese]. 2008, National Assembly: Hanoi, Vietnam.

3. Thu, V., et al., Drug Policy in Vietnam: A Decade of Change? International Journal of Policy Analysis, 2012. 23: p. 319-26.

4. National Committee on Social Affairs, Vertification's Report on Draft Law on Drug Control and Prevention with Supplement and Amendment [Vietnamese]. 2008, National Assembly: Hanoi, Vietnam.

5. National Assembly, The Amendment and Supplement a Number of Articles of the 1999 Criminal Code of Vietnam, in No.37/2009/QH12, National Assembly of Vietnam, Editor. 2009: Hanoi, Vietnam.

6. Human Rights Watch, Vietnam: The Rehab Archipelago - Forced Labor and Other Abuses in Drug Dentention Centers in Southern Vietnam. 2011, Human Rights Watch: New York.

7. Thu, V., et al., Outcomes of Compulsory Detention Compared to Community-Based Voluntary Methadone Maintenance Treatment in Vietnam. Journal of Substance Abuse Treatment, 2018. 87(April): p. 9-15.

8. Thu, V., et al., The Political and Scientific Challenges in Evaluating Compulsory Drug Treatment Centers in Southeast Asia. Harm Reduction Journal, 2017. 14(2): p. 1-14.

9. MOLISA, Overview of the impact of policies on drug rehabilitation treatment on its implementation in Vietnam. 2010, Ministry of Labor, Invalids and Social Affairs (MOLISA): Hanoi, Vietnam. 
10. Chung, D., C. Nguyen, and T. Trung. Bo Cong an: Can nhac khoi phuc quy dinh xu ly hinh su nguoi su dung ma tuy [trans: Ministry of Public Security: Rethinking on Re-criminalize Drug Use]. 2019 [cited 20195 June]; 4 June:[Available from: https://baomoi.com/bo-cong-an-can-nhac-khoi-phuc-quy-dinhxu-ly-hinh-su-nguoi-su-dung-ma-tuy/c/30972414.epi.

11. Donnelly, N. and W. Hall, The Effects of Partial Decriminalisation on Canabis Use in South Australia, 1985 to 1993. Australian Journal of Public Health, 1995. 19(3): p. 281-287.

12. Fetherston, J. and S. Lenton, Effects of the Western Australian Cannabis Infringement Notice Scheme on Public Attitudes, Knowledge and Use: Comparison of Pre- and Post-Change Data. 2007, Perth, Australia: National Drug Research Institute.

13. Zhao, X. and M. Harris, Demand for Marijuana, Alcohol and Tobacco: Participation, Levels of Consumption and Cross-equation Correltions. The Economic Record, 2004. 80(251): p. 394-410.

14. Williams, J., The Effects of Price and Policy on Marijuana Use: What Can Be Learned from the Australian Experience. Health Economics, 2004. 13: p. 123-137.

15. Pacula, R., J. Chriqui, and J. King, Marijuana Decriminalization: What Does It Mean in the United States?, in Working Paper Series, National Bureau of Economic Research, Editor. 2003, National Institute on Drug Abuse: Massachusetts, Maryland.

16. Hall, W. and J. Lucke, Drug Decriminalization and Legalization. Interventions for Addiction: Comprehensive Addictive Behaviors and Disorders, ed. P. Miller. 2013, London: Academic Press.

17. Hughes, C. and A. Stevens, What Can We Learn from the Portugues Decriminalization of Illicit Drugs? Brit. J. Criminology, 2010. 50(1): p. 999-1022.

18. Windle, J., The Slow March to Harm Reduction: Drugs and Drug Policy in Vietnam. Journal of Drug Policy Analysis, 2016. 10(2): p. 483-495.

19. Tomori, C., et al., "In their Perception We Are Addicts": Social Vulnerabilities and Sources of Support for Men Released from Drug Treatment Centers in Vietnam. International Journal of Drug Policy, 2014. 25(5): p. 897-904.

20. MOLISA, Bao cao Ket qua cong tac cai nghien phuc hoi nam 2010 [trans: Annual Report 2010 on Drug Rehabilitation's Works]. 2011, Department of Social Affairs, MOLISA: Hanoi, Vietnam.

21. USAID, PEPFAR, and FHI360, Effectiveness Evaluation of the Pilot Program for Treatment of Opioid Dependence with Methadone. 2014, FHI360: Hanoi, Vietnam.

22. Tam, T.M.N., et al., Methadone Maintenance Therapy in Vietnam: An Overview and Scaling-Up Plan. Advances in Preventive Medicine, 2012. 2012: p. 1-5.

23. Trang, T.N., et al., Struggling to Achieve a 'Normal Life': A Qualitative Study of Vietnamese Methadone Patients. International Journal of Drug Policy, 2019. 68(June): p. 18-26.

24. Jardine, M., T.V.N. Anh, and T.K. Hong, Case Study: Methadone Maintenace Treatment in Hanoi, Vietnam. Harm Reduction Journal, 2012. 9(26): p. 1-2.

25. Dung, T.T., A Critical Exploration of Professional Perceptions of Harm Reduction Policy and Practice in Vietnam. 2019, Victoria University of Wellington: Wellington, New Zealand. 
26. Jardine, M., et al., Harm reduction and law enforcement in Vietnam: influences on street policing. Harm Reduction Journal, 2012. 9(27): p. 1-10.

27. Hong, T.K., et al., Harm Reduction and "Clean" Community: Can Viet Nam have Both? Harm Reduction Journal, 2012. 9(25): p. 1-10.

28. MPS, Draft National Report on 10 Years to Implement Law on Drug Control and Prevention [Vietnamese], General Office of MPS, Editor. 2019, Ministry of Public Security (MPS): Hanoi, Vietnam.

29. MPS, Draft Report on Analyzing Policy's Impacts to Propose in Law Drug Control and Prevention (Supplementation and Amendment) [Vietnamese], General Office of MPS, Editor. 2019, Ministry of Public Security (MPS): Hanoi, Vietnam.

30. Collins, S., H. Lonczak, and S. Clifasefi, Seattle's Law Enforcement Assisted Diversion (LEAD):

Program Effects on Recidivism Outcomes. Evaluation and Program Planning, 2017. 64: p. 49-56. 